\title{
DESIGN E ENVELHECIMENTO SAUDÁVEL: EMPREENDEDORISMO DEPOIS DOS 50
}

\author{
Maria Isabel Mariz May Carmo \\ Pontifícia Universidade Católica do Rio de Janeiro \\ mabelmariz@gmail.com \\ Bárbara Alves Betts \\ Pontifícia Universidade Católica do Rio de Janeiro \\ barbarabettspuc@gmail.com \\ Mariana Peixoto Gonçalves Pereira \\ Pontifícia Universidade Católica do Rio de Janeiro \\ mari.pg.pereira@gmail.com \\ Vera Maria Marsicano Damazio \\ Pontifícia Universidade Católica do Rio de Janeiro \\ vdamazio@puc-rio.br
}

Resumo: Este trabalho se insere em estudo sobre o potencial do campo conhecido como Design Emocional em contribuir para a promoção do envelhecimento saudável. Ele partiu da constatação de que a população brasileira está envelhecendo e vivendo cada vez mais, mas suas demandas não estão sendo entendidas, nem atendidas como deveriam pelo Design. Estudos qualitativos sobre o público com mais de 60 anos como o livro de Mirian Goldenberg "A Bela Velhice" apontam que está ocorrendo um processo de transformação do entendimento sobre o conceito de velho e a velhice passando a ser considerada a fase da vida não mais apenas de perdas e doenças, mas também de conquistas, realizações e, sobretudo, de novas experiências e projetos. Apesar do gradativo deslocamento das perdas e aspectos negativos para os ganhos e aspectos positivos, o envelhecimento da população no Brasil ainda é fortemente associado à perda de renda e improdutividade, sendo um dos possíveis caminhos para reverter esta situação a criação de oportunidades de participação dos idosos no mundo do trabalho. Neste sentido, este trabalho tem como principal objetivo identificar meios de atuação do design em prol do envelhecimento economicamente ativo e levantar exemplos de ações com foco em Empreendedorismo para esse público. Este pôster, por sua vez, tem por fim apresentar parte do acervo de ações pesquisadas e localizadas em buscas na internet a partir do cruzamento de palavras-chave em português e inglês relacionadas aos três temas centrais: envelhecimento, empreendedorismo e a atividade do design. As ações a serem apresentadas são: (1) MaturiJobs, que se define como um novo serviço para "ajudar pessoas acima de 50 anos a encontrar uma nova ocupação ou recolocação, tanto profissional quanto de forma autônoma" e se concretiza 
por meio de plataforma de economia colaborativa; (2) Mulheres +50 em Rede, que se apresenta como "uma iniciativa apoiada em 3 pilares: empreendedorismo feminino, capacitação digital e criação de uma rede colaborativa de Mulheres $50+$ e se dá sob a forma de cursos para participantes que já tenham um pequeno negócio e (3) The Amazings, que se apresenta como um empreendimento social que permite que aqueles que estão prestes a se aposentar, ou que já tenham se aposentado, compartilhem com outros algumas de suas habilidades e conhecimento acumulado e tem por fim trazer essas pessoas de volta para a malha social. Esta iniciativa se concretiza por meio de plataforma que possibilita tal compartilhamento de conhecimentos e habilidades no formato de cursos de pequena ou longa duração, que custam entre $£ 10$ e $£ 25$. Esta ação foi gerada no âmbito do Independence Matters - desafio promovido pelo Design Council em parceria com a Innovate UK com o propósito de incentivar o desenvolvimento de serviços que promovam independência na maturidade.

Palavras-chave: design social; design emocional; envelhecimento saudável; empreendedorismo 